\title{
Recapacitando sobre formación y evaluación de competencias en una escuela de ingeniería de biosistemas y agroalimentaria.
}

Fabregat, J. ${ }^{\text {a }}$ y Pineda, E. ${ }^{\text {b }}$

${ }^{a}$ Coordinador de competencias genéricas, Escola Superior d'Agricultura de Barcelona (UPC), jaime.fabregat@upc.edu, y bJefe de Estudios, Escola Superior d'Agricultura de Barcelona (UPC), eloi.pineda@upc.edu

\begin{abstract}
The engineering schools have already graduated the first students within the framework of the EHEA. The new curricula, designed with the aim of European convergence, require training oriented to the learning of generic skills. In the first stage of curricula design, the engineering schools identified the necessary generic and specific skills to be achieved during the learning process. Each school defined and characterized its own process of training and evaluating them.

The aim of this communication is to open a conscious analysis of the training and assessment processes of generic skills in the School of Agricultural Engineering of Barcelona at Universitat Politecnica de Catalunya. These processes are similar in other centers and universities and emphasis is given to their definition and evaluation in order to be reoriented and adapted within the engineering curricula.

The three objectives of the work are: 1) Clarify the sense of the generic skills; 2) Analyze the training aspects; 3) Introduce the necessity of an evaluable generic-skillsprofile of the university students.
\end{abstract}

Keywords: competence, convergence, profile, transversality

\footnotetext{
Resumen

Las escuelas de ingeniería disponen ya de una primera promoción en el marco EEES. Los planes de estudio de los grados nacidos a partir de la convergencia europea requieren que la formación del universitario se oriente a la formación en competencias. Así, las escuelas realizaron previamente, en su momento, la identificación de competencias genéricas necesarias para el alcance de las metas de
} 
Recapacitando sobre formación y evaluación de competencias en una escuela de ingeniería de biosistemas y agroalimentaria

todos sus estudios y la formulación de las competencias específicas orientadoras de cada grado. Cada centro ajustó su propio proceso para caracterizarlas y expresarlas.

La presente comunicación responde a la apertura de un análisis reflexivo, de base y global, acerca de las competencias genéricas en la Escola Superior d'Agricultura de Barcelona, que son en gran medida análogas a las de otros centros y aún universidades, con énfasis en su propia definición y evaluación, todo ello en el marco de un proyecto para reorientar su encaje en el currículum.

El objeto de la aportación es triple: por una parte, esclarecer el sentido de las competencias; en segundo lugar, incidir sobre aspectos formativos acerca de ellas; en tercer lugar, plantear la necesidad de un perfil competencial significativo y evaluable del estudiante universitario a partir de interpretar datos precedentes.

Palabras clave: competencia, convergencia, perfil, transversalidad

\section{Introducción}

En cuanto a las competencias genéricas, o transversales, cerrado ya el ciclo de una primera promoción de graduados y dada la novedad de su presencia explícita en el escenario, tiene sentido proceder a su examen, así como a un análisis de la metodología seguida para la formación. El camino seguido en este primer pase para apoyar su alcance y para evaluar el grado de su adquisición ha tenido consecuencias diversas - sobre docentes y discentes - que conviene observar y estudiar, adoptando para ello un razonable espíritu crítico.

La Escola Superior d'Agricultura de Barcelona imparte grados i masters en el marco de la ingeniería de biosistemas. Fue una de las escuelas pioneras en desarrollar sus enseñanzas bajo el paraguas del EEES y, por tanto, en contar con un balance de competencias. En cuanto a las competencias genéricas incorporó operativamente las siete que la Universitat Politècnica de Catalunya marcó como comunes (aprendizaje autónomo, comunicación eficaz oral y escrita, innovación y espíritu emprendedor, sostenibilidad y compromiso social, tercera lengua, trabajo en equipo, uso solvente de recursos de información) y añadió como propia la competencia de resolución de problemas.

\section{Objetivos}

Dentro de la autonomía de cada centro cabe plantearse adoptar decisiones de diversa trascendencia, desde incluso alguna exclusión y/o inclusión de competencias hasta, en mayor 
medida, replanteamientos en lo que se refiere al dónde, al cuándo, al cómo y al quién ejecuta acciones preparatorias y de evaluación de las mismas. Ésta ha sido la razón que ha impulsado a que la "Escola Superior d'Agricultura de Barcelona" haya generado la nueva figura de "coordinador de competencias genéricas" y a que ésta haya elaborado un cuaderno de trabajo relativo a las competencias genéricas.

La presente aportación ofrece consideraciones varias en el campo citado, de carácter reflexivo, que por sus características pueden ser fácilmente transferibles a otros contextos más allá del centro específico del que han surgido. Su contenido enlaza con el proyecto de investigación "El impacto de la evaluación educativa en el desarrollo de competencias en la universidad. La perspectiva de las primeras promociones de graduados" (Plan Nacional de I+D+i . Subprograma de Proyectos de Investigación Fundamental).

\section{Desarrollo de la innovación}

Partiendo de documentos y alzando un vuelo sobre escritos diversos, se han seleccionado y distinguido unos puntos sobre los que recapacitar, madurar y deliberar, con objeto de avanzar en la prestación de un servicio dirigido a conseguir los objetivos mencionados.

\subsection{Referencias básicas}

1. La Comisión Europea definió "competencia” como "conjunto de conocimientos, destrezas y actitudes que todos los individuos necesitan para su realización y desarrollo personal, inclusión y empleo”. Existen otras muchas definiciones, más o menos próximas o similares, y más o menos ligadas a la inclusión laboral.

2. Calidad educativa se puede entender como formación de hombres y mujeres competentes para los demás, de manera que ello se manifieste a partir del aporte que tendrán los graduados en la vida social, desde el ámbito de la profesión, para la cual se habrá intensamente procurado una instrucción teórica y técnica .

3. Un imperativo biológico de encontrar un sentido superior a las cosas existe en el ser humano, que posee una competencia genérica para lo prodigioso.

4. La "competencia” se fragmenta en un conjunto de competencias para abordar su formación y su evaluación. Hay debate sobre los elementos y el cardinal de este conjunto.

5. Sobre la formación por competencias una discusión sigue abierta. Cabe amasar que en 2001 Barnett a escala internacional y en 2008 Escudero en España ya la cuestionaban.

6. La identificación de las competencias necesarias depende de entorno, tiempo y coyuntura.

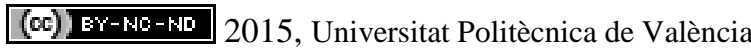

Congreso In-Red (2015) 
Recapacitando sobre formación y evaluación de competencias en una escuela de ingeniería de biosistemas y agroalimentaria

7. Estudios de agencias han mostrado la gran dificultad sentida para realizar una inserción laboral rápida, en parte por las fallas en cuanto a competencia, las cuales se traducen en pérdida de oportunidades.

8.Un amplio estudio sobre el impacto de la evaluación educativa en desarrollar competencias ha probado que la mayoría de docentes no evaluaba por competencias: tal evaluación sufre un rechazo.

9.Profesores que no evaluaban por competencias han aducido esperar indicaciones institucionales, con directrices, y no sentirse preparados.

10.La evaluación actual sigue sin percibirse ni como experiencia, ni como parcela, de una metodología de aprendizaje de las competencias.

Cabe señalar que el punto de partida del diseño actual, sobre el que ahora se abre el propósito de reorientación, optó por encajar las competencias genéricas, mediante impregnación, dentro de un conjunto de asignaturas previamente identificadas del plan de estudios, cuyos objetivos mayoritarios y definitorios respondían a unas competencias específicas. Hubo un decantamiento hacia una estructura de tres niveles competenciales partiendo de unos estándares básicos, en el entorno de los cuales se iría constatando el avance de los estudiantes, a tenor de lo que éstos mostraran en una parrilla (o puzzle) de actividades específicas que se desarrollarían al amparo de las disciplinas. Este diseño se ha llevado a la práctica durante los primeros seis años de los grados EEES del centro y ahora se analiza.

\subsection{Enfoques del profesorado}

Por parte de los profesores, ¿cuáles son los puntos de vista desde la especulación, y cuáles son los signos desde las acciones, sobre la anexión de las competencias genéricas en la formación universitaria en el marco del EEES?

Se confronta que es variada la posición inicial de los docentes en cuanto a tener responsablidades concretas - hasta cierto punto separadas de sus responsabilidades en torno a la disciplina - en lo que concierne a contribuir a la generación de adelanto en competencias genéricas. Un sector pequeño se muestra en condiciones, cuenta estar especialmente complacido y proclive a ello, y entiende que lo que se le pide combina con las normas y el talante de la asignatura que imparte y con su propio deber y talante personal. Otro pequeño sector se situa en las antípodas y ve esa contribución como algo impuesto y antinatural, y que dificílmente encaja con su disciplina y su modo de impartirla. En medio se encuentra la mayoría del profesorado, que sin alegrías pero tampoco con penas, sin euforia pero tampoco con rabia, se ha aprestado a colaborar en la tarea.

(c)) EY-NC-ND 2015, Universitat Politècnica de València

Congreso IN-RED (2015) 
Con el paso del tiempo el profesorado contrario no ha cambiado su posición: o bien se ha resignado a un cumplimiento formal de sus obligaciones y/o a un cumplimiento actual de minimos, o bien ha intentado encauzar argumentadamente cambios en un proyecto integrador.

Por el contrario, el profesorado más sensible a la relevancia de las competencias genéricas ha ido advirtiendo lagunas y agujeros en cuanto a los logros esperados, y ha procurado poner énfasis sobre la necesidad, no sólo de no bajar la guardia, sino de mover ficha en un sentido positivo, sea con pequeños cambios, sea con modificaciones estructurales. También en algún caso profesores muy predispuestos por la causa se han venido abajo al observar que debido a la disposición del alumnado, o al contexto general, los grandes sobreesfuerzos que había aplicado caían en saco roto, generando una imagen de tiempo perdido e insuficientemente reconocido o agradecido.

Aparte, existe un conjunto de docentes que ha visto que con el transcurso del tiempo las condiciones de contexto pasaban a ser considerablemente distintas y que, en general, se les hacía muy cuesta arriba ser capaces de mantener sus compromisos, a tenor de reducciones de dotación de profesorado y/o al aumento de estudiantes a los que debían igualmente atender.

\subsection{Nuevos impulsos}

El soporte, el seguimiento y la cordinación relativa a las competencias genéricas ha sido una tarea más de las que ha recaido sobre la jefatura de estudios. La problemática recogida en párrafos anteriores ha impulsado en el presente año académico a la escuela a plantear la generación de una nueva figura específica dentro de la estructura: el coordinador de competencias genéricas, dependiente en primera instancia de la propia jefatura de estudios..

De común acuerdo, ambos han abierto un proceso marcado por la consecución de dos objetivos. Uno de ellos, de urgencia, consiste en ir derecho a "apagar fuegos", buscando alternativas equitativas e inmediatas para el próximo curso que permitan hacer frente, cuando menos de modo transitorio, a acciones en peligro de abandono por diversas circunstancias. Pero el objetivo fundamental es reflexionar con profundidad sobre el pasado y el presente, con las miras puestas en reorientar las actividades en el futuro.

\subsection{Elementos de atención}

Uno de los puntos, sobre los que se ha puesto especial insistencia, es la consideración de que el prisma de cuidado sobre las competencias se ha movido hasta ahora más en el terreno de la búsqueda de fórmulas que acrediten sus niveles de logro y sus avances, que en el terreno

\section{(cc) EY-NC-ND 2015, Universitat Politècnica de València}


Recapacitando sobre formación y evaluación de competencias en una escuela de ingeniería de biosistemas y agroalimentaria

de una formación en cuanto a las mismas. Se ha pensado que mirando hacia el futuro hay que diseñar una preparación en competencias genéricas, que contemple una evaluación formativa y una acreditativa, pero que no ha de ser esta última el núcleo duro sobre el que fijar la máxima atención, sino que sobre todo hay que procurar la formación.

Otro punto importante es tomar nota y tener en cuenta que ningún estudiante parte de cero en lo que concierne a tales competencias y que tiene sentido percatarse de que importa el estadio inicial (en lo que resulta común o mayoritario en los estudiantes , y en lo que existe de heterogeneidad). Hay que esforzarse a la vez por diferenciar lo "innato" y lo "adquirido" y regularizarlo, en distinguir lo que persiste y lo que muda.

Una tercera cuestión es si procede plantearse una mera continuidad del sistema de formar en competencias por impregnación dentro de asignaturas con otros objetivos específicos o si procede incorporar asignaturas u otras fórmulas específicas de complementariedad, que se centren en gran medida sobre alguna o algunas de las competencias genéricas (materias optativas, ciclos de conferencias y debates, apertura de espacios específicos en el campo virtual, ...). . Dicho con otras palabras, si procede seguir con un sistema puro de impregnación o si se diseña un sistema mixto combinando el actual con una estrategia para la formación en paralelo.

Un punto más es valorar la posibilidad de reconocer explícitamente como formadoras ( e incluso acreditadoras de facto) acciones realizadas extramuros de la escuela, de la mano de otras instancias, con las que acaso establecer alianzas en algunos supuestos.

Dada la complejidad y envergadura del asunto, por más que se examine y se replantee el conjunto del proceso a lo largo de toda la estructura de los estudios, se ha decidido poner énfasis en algunas de las competencias generícas así como hacer hincapié en modificaciones que sea viable diseñar e implementar ya para el primer año académico del próximo curso (en sus dos cuatrimestres), dando un inmediato pistoletazo de salida para que la nueva promoción de estudiantes ya se incorpore a la forma renovada de alcance de los supuestos.

Como resultado del análisis del diseño actual y la correspondiente reflexión, se proponen algunos elementos básicos dentro de un nuevo diseño para la formación y evaluación de competencias genéricas en los planes de estudio del centro.

\subsection{La competencia de compromiso social}

La competencia de compromiso social (con este nombre u otros parecidos) se halla referenciada en numerosas universidades, y a la misma conciernen valores, actitudes y ética, además de otros conceptos. Hay investigación que la señala de facto como una de las “competencias olvidadas”. En grados de ingeniería acaso la razón estribe en la mayor 
dificultad para su inserción efectiva en disciplinas de ciencia y tecnología "pura y dura” que dominan en los planes de estudios, sobre todo en los primeros años académicos.

Muchas veces la competencia de compromiso social va de la mano de la sostenibilidad, y ante la potencia de la cara medioambiental de la misma, su cara humano/social queda diluida y parcialmente desamparada.

Numerosos profesores ven difícil el alta por impregnación de la competencia de compromiso social dentro de disciplinas científicas básicas como matemáticas, física, química, ... o de disciplinas instrumentales como expresión gráfica, laboratorio, .... que son mayoritarias en los primeros cursos académicos. Suele verse más fácil la posibilidad de concentrar su presencia en materias ligadas a la economía y a la administración de empresas - a veces también en proyectos de ingeniería -, asignaturas que suelen hallarse en los últimos cuatrimestres

Hay quienes entienden que el compromiso social entra dentro del terreno de las convicciones personales íntimas, y que su despliegue en las aulas puede tener un halo de adoctrinamiento por lo que se resisten a su inclusión.

La medición de variables sociotécnicas, gobernandose por los aparejos de que se dota gradualmente la especie humana, es algo conocido, pero no esta todavía a nuestro alcance al mismo nivel que la medición de variables técnicas. Por recelos o temores ante un abandono de sus "seguridades", el ciudadano del país de la técnica puede sentirse frenado a dejar sus territorios.

¿Por dónde y cómo se puede empezar? ¿Qué se puede esperar a cortoplazo?

a)Abrir los ojos

Mediante una actividad expositiva programada en los primeros días de clase, aprovechando los primeros contactos del estudiante con le escuela de ingeniería, (y sacando partido de los agujeros que suelen dejar la inexistencia de prácticas en las primeras jornadas), cabe emplazar guiadamente al estudiante hacia una definición de ingeniería. De una forma constructiva se puede mostrar que el ingeniero precisa una preparación ineludible en materias científicas básicas y en materias tecnológicas que le permitan encontrar soluciones técnicas a retos diversos, pero procede mostrarle también que finalmente deberá elegir cual de las soluciones técnicas adopta o propone, y aquí es donde su jerarquía de valores será la que decida: aquí el compromiso social jugará una gran baza.

b)Impulsar la reflexión inicial

Corresponde promover la meditación en torno a los temas antes indicados. Para ello, y transcurridas unas semanas tiene sentido solicitar de los estudiantes (a título individual o por pequeño grupo) la elaboración de un texto que incorpore reflexiones personales o grupales en cuanto a este asunto, o que recoja impresiones generadas por lecturas aconsejadas.

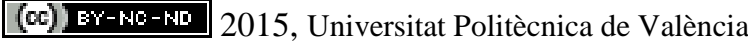


Recapacitando sobre formación y evaluación de competencias en una escuela de ingeniería de biosistemas y agroalimentaria

c)Proponer actitudes adecuadas

Mediante la asistencia a un "discurso" expositivo, y mediante la praxis interna, enasignaturas, procede justificar, emplazar y valorar actitudes. Por ejemplo, en matemáticas, es fácil argumentar la necesidad de la humildad (nos equivocamos), de la prudencia (conviene activar mecanismos que descubran la existencia de posibles errores), del pensamiento crítico (analicemos con el uso de la razón lo que hemos hecho, y quizá así descubramos el porque de los errores), del rigor (así será menos fácil incurrir en errores, ...).

Y en cuanto a actitudes sociales procede hacer ver al estudiante cuestiones tales como que sus resultados serán distintos según el punto en el que se situe entre la noción genérica de hombre y la persona singular, que no son cuentos los conflictos de competencias, que no es oportuno embargar una notoria sabiduría popular, ...

d)Mostrar la existencia de códigos de deontología

Nos hallamos ante una espesa red de reglas en las compañías, comúnmente en aquiescencia con el medio. En el marco concreto de las ingenierías, como "garantes" de ciertos comportamientos, no sólo “ante, en y/o frente” a las compañías, sino también en relación con la sociedad, son ya numerosos los códigos éticos existentes. Es bueno comparar la graduación entre lo "malo" que suelen establecer los estudiantes y la graduación entre lo "malo” que suelen recoger los códigos. La investigación empuja a efectuar las comparaciones, ya que ha constatado que se dan imágenes curiosas.

Todo lo que antecede puede ser germen de procesos de evaluación formativa y fuente de indicadores para una evaluació acreditativa, en cuanto a condiciones y contenidos de carácter ético, en cuanto al conocimiento moral humano.

\subsection{La competencia de comunicación}

La competencia de comunicación es una de las que provoca en el profesorado el envío de más señales de alerta acerca de agujeros y lagunas en los estudiantes próximos a dejar ya su andadura unversitaria. No son pocas las voces de alarma que levantan tutores con ocasión de la elaboración por parte de los estudiantes de sus trabajos de grado, en los que se obsevan a menudo claras deficiencias comunicativas como, por ejemplo, que un texto no responda a una estructura, mientras que acaso por otro lado sí que exista la capacidad de diseñar un recurso multimedia en red.

Es característico que sobre el papel se enfatice sobre la comunicación “oral” y “escrita”, como ya se formulaba décadas o incluso centurias atrás. Pero hoy la comunicación alberga un espectro más amplio y entrelazado: el papel de la imagen es incuestionable, ¿cuánta 
lectura y escritura hay en la red?, el mejor profesional puede ver malogrado su saber si no se maneja como es necesario en una red de relaciones, ...

Cuando se habla de competencia en comunicación oral generalmente se hace hincapié en la capacidad discursiva: de hablar correctamente, de efectuar buenas presentaciones, de formular plegarias educadas,... Se pone el acento en la propia independencia del estudiante como emisor. No obstante, y como es bien sabido, no hay comunicación sólo con emisor. El papel de receptor también es clave: escuchar bien, ... Y es particularmente remarcable el papel doble emisor - receptor: de referirse a lo que otro dijo, de interactuar verbalmente de modo eficaz con personas de otras áreas, ...

Consideraciones análogas cabe fundamentar para llevar a cabo peticiones en cuanto a la comunicación escrita. Estaríamos en este caso ante la necesidad no sólo de redactar bien, de generar recursos en red bien, ... sino también de leer bien, de interpretar bien un texto y otros paralelos temáticos.

De lo que antecede se desprende que cuestiones como la participación y la dirección en reuniones, el tratamiento de los rumores, la acomodación a los interlocutores, ... son aspectos que no tiene sentido olvidar.

$\mathrm{Y}$, ¿qué decir de que un futuro ingeniero carezca de actividades formativas concernientes a la comunicación en las nuevas fronteras tecnológicas, con sus promesas, desafíos y amenazas?

¿Por dónde y cómo empezar? ¿Qué se puede esperar a corto plazo?

a)Abrir los ojos

Mediante una actividad expositiva programada en los primeros días de clase, aprovechando los primeros contactos del estudiante con le escuela de ingeniería, (y sacando partido de los agujeros que suelen dejar la inexistencia de prácticas durante las primeras jornadas) , estacionar guiadamente al estudiante ante el fenómeno general de la comunicación, pasando luego a la comunicación dentro de las organizaciones, a la comunicación dentro de pequeños grupos, hasta llegar al diálogo. Cabe comprender el papel de cada uno en un encuentro comunicativo del arquetipo muchos - muchos, muchos - uno, no - muchos, uno - uno, y variantes.

b)Impulsar la reflexión inicial

Corresponde promover la meditación en torno a los argumentos precedentemente indicados. Para ello, incumbe que transcurridas unas semanas "áfonas" adquiera un sentido solicitar, a título individual o de pequeño grupo, que los estudiantes originen un texto elaborado que incorpore reflexiones personales o grupales en torno a este asunto, o que amontone impresiones concebidas por lecturas que hayan sido sugeridas. (“Comunicación” sobre “comunicación”)

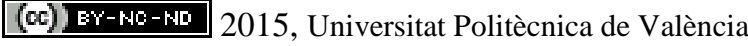


Recapacitando sobre formación y evaluación de competencias en una escuela de ingeniería de biosistemas y agroalimentaria

a)Estimular habilidades adecuadas

Mediante la disertación, pero mejor mediante la praxis interna en asignaturas, emplazar a la utilización de habilidades que mejoren la comunicación oral (mucho más allá de la mera articulación de sonidos), tanto para quien ejerce el papel de emisor como para quien ejerce el papel de receptor.

b)Enfocar primeros pasos de comunicación escrita científico - técnica

Diversas asignaturas pueden indicar que en actos de evaluación formales habrá alguna pregunta en la que se pida la definición de un vocablo o el enunciado de un teorema, mediante verbalización (omitiendo fórmulas, acrónimos, gráficos, ...)

Y en un segundo eslabón se pondrá al estudiante ante la tesitura de entrar a ver si la introducción de algún vocablo por parte de una tercera persona coincide con el uso común (o un uso referenciado) del mismo. O ídem con el enunciado de un teorema.

Lo que antecede puede ser germen de procesos de evaluación formativa y fuente de indicadores para una evaluació acreditativa.

\section{Resultados}

He aquí consecuencias de aplicar procesos de reflexión como los apuntados anteriormente con una clara voluntad de aplicación al marco de la ingeniería.

Atender demandas complejas en una trama concreta exige movilizar prerrequisitos psicosociales que incluyen aspectos tanto cognitivos como no cognitivos. Una escuela de ingeniería no debe pensar sólo en formar y tutorar en ciencias y en tecnologías.

La aptitud pedagógica se concibe como la capacidad de ayuda a "uno" con objeto de que sea competente para "el otro". Una escuela de ingeniería no ha de tratar solamente en los planes de estudios las materias científico-tecnológicas y su desarrollo, sino que ha de pretender pensar en los perfiles humanos de los profesionales que requiere la sociedad hoy y en el futuro, al servicio de unas mejores formas de vida y convivencia.

Es imperioso para el hombre hallar sentido a los sucesos; la persona tiene una competencia genérica para lo maravilloso. Una escuela de ingeniería no debe conformarse con presentar hechos y quedarse en lo corriente de la existencia, sino que ha de procurar sacar provecho de posibilidades relevantes de la arquitectura cerebral humana.

Resolver una tarea en un contexto reclama usar muchos recursos (habilidades, actitudes, conocimientos y experiencias); no sirve cualquier conjunto de recursos ni toda forma de usarlos. Una escuela de ingeniería no debe pensar sólo en términos de disciplinas disjuntas, sino también de tareas conjuntas.

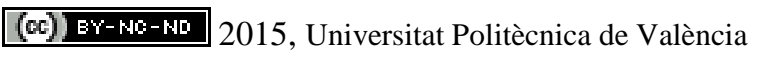


Se enfatiza en que hay que contar con personas de alto nivel de conocimientos, así como alto nivel de habilidades para resolver problemas auténticos de la profesión. Una escuela de ingeniería no debe pensar sólo en preparar sobre la base de ejercicios meramente académicos sino en ubicar a los estudiantes en contextos propios de la vida real.

De los profesionales se requiere competencia en formular preguntas, buscar y usar información relevante, realizar observaciones precisas, analizar datos, pensar críticamente, elaborar juicios, resolver problemas, generar novedades, comunicar oralmente y por escrito. Una escuela de ingeniería no debe pensar sólo en que el estudiante vaya almacenando contenidos que originalmente son de otros, sino en que él mismo los alcance, estructure, elabore, dé sentido, aplique y transmita.

Se pide en los profesionales que posean competencias sociales, como conversar, debatir, acompañar, trabajar en grupo, convencer o dirigir. Una escuela de ingeniería no debe pensar sólo en promover "omnisciencias individuales", sino en formar estudiantes abiertos y preparados para el diálogo, el convenio y la asistencia, y también, cuando proceda, la persuasión, el liderazgo, el gobierno.

A las personas se demandan también disposiciones afectivas, perseverancia, motivación, compromiso, autoeficacia, independencia o flexibilidad. Una escuela de ingeniería no debe pensar sólo en formar en conceptos y en procedimientos sino también en actitudes, y no echar en olvido el papel de emociones y sentimientos.

Se solicita que los profesionales posean competencias no meramente cognoscitivas sino también metacognitivas, que lleven a pensar en qué hacen, en cómo, por qué y para qué (y/quién) lo hacen y en el valor de lo que hacen. Una escuela de ingeniería no debe pensar sólo en los procesos de heteroevaluación aplicados a los alumnos sino también en fomentar la autorreflexión y la autoevaluación en los estudiantes.

\section{Conclusiones}

La transferencia de lo que antecede a una escuela de ingeniería en biosistemas conduce primero a constatar que las competencias genéricas aquí citadas tienen sentido en ella, que es clave velar, pues, por su formación y que hay que facilitar aspectos de una evaluación general, para lo cual procede - y cabe - encontrar fuentes variadas, con especial atención a las tareas, así como establecer oportunos criterios en el desarrollo de los diseños curriculares. Todo ello constituye un conjunto de aventuras ( y seguramente también de desventuras) en el reino de la formación en ingeniería. 
Recapacitando sobre formación y evaluación de competencias en una escuela de ingeniería de biosistemas y agroalimentaria

\section{Referencias}

ALONSO, L.E. et al. (2009), El debate sobre las competencias. Una investigación cualitativa en torno a la educación superior y el mercado de trabajo en España,. Madrid : Agencia Española de Evaluación de la Calidad y Acreditación - ANECA

BARNETT, R., (2001), Los límites de la competencia. El conocimiento, la educación superior y la sociedad, Barcelona : Gedisa

BOLIVAR, A. (2000), Los centros educativos como organizaciones que aprenden, Madrid : La Muralla

COROMINAS, E. et al. (2006), R. Percepciones del profesorado ante la incorporaciónde las competencias genéricas en la formación universitaria en Revista de Educación, vol. 341, p. 301- 336

DEBRAY, R. (2005), Dios. Un itinerario : Materiales para la historia del Eterno en Occidente, México : Siglo XXI editores

ESCUDERO, J.M., VALLEJO, M., BOTIAS, F. (2008) El asesoramiento en educación : ¿Podrían ser las competencias profesionales una contribución positiva ? en Profesorado. Revista de Currículum y Formación del Profesorado. Disponible en http://www.ugr.es/ recfpro/rev121ART2.pdf [Consulta: 2015, 30 de mayo]

GAINES, D., y ROBINSON, J. C. (1999), Consultoría del rendimiento : Más allá de la formación. Madrid : Editorial Ramón Areces

GIMENO, J. (Comp.), (2008), Educar por competencias, ¿qué hay de nuevo ?, Madrid : Morata

KIRKPATRICK, D.L. (1999), Evaluación de las acciones formativas. Los cuatro niveles. Barcelona : EPISE 